\title{
IJAHSP:-
}

The Internet Joưnal of Allied Health Sciences and Practice

A Peer Reviewed Publication of the College of Health Care Sciences at Nova Southeastern University

Dedicated to allied health professional practice and education

http://ijahsp.nova.edu Vol. 11 No. 4 ISSN 1540-580X

\section{Role-Emergent Model: An Effective Strategy to Address Clinical Placement Shortages}

\author{
Rosemin Kassam, B.Sc.Pharm., ACPR, Pharm.D. ${ }^{1}$ \\ Mona Kwong, B.Sc.(Pharm), M.Sc. ${ }^{2}$ \\ John B. Collins, Ph.D. ${ }^{3}$
}

1. Associate Professor, Faculty of Medicine, School of Population and Public Health, University of British Columbia, Vancouver, BC

2. Researcher, Faculty of Pharmaceutical Sciences, University of British Columbia, Vancouver, BC

3. Adjunct Professor, Department of Educational Studies, University of British Columbia, Vancouver, BC

Canada

CITATION: Kassam R, Kwong M, Collins J. Role-Emergent Model: An Effective Strategy to Address Clinical Placement Shortages. The Internet Journal of Allied Health Sciences and Practice. Oct 2013. Volume 11 Number 4.

ABSTRACT

Purpose: To evaluate the effectiveness of an advanced pharmacy practice experience (APPE) delivered at "role-emergent" placement sites within long-term care (LTC) facilities that are preceptored by off-site community pharmacists. Method: Seven LTC facilities participated: five newly recruited test sites preceptored by off-site pharmacists who supervised students remotely ("role-emergent" placements), and two previously established hospital-based facilities with on-site pharmacists who provided continuous student supervision ("role-established" placements) as a comparison group. Students participated in pre-APPE training. Both qualitative and quantitative methods were used to obtain student learning performance on 13 pre-defined learning objectives and 21 indicators of site resources and skills-development opportunities. Structured open-ended feedback questions and reflective student observations elicited more personal and situational experiences. These combined with faculty reviews of student documentation of their patient care delivery encounters and LTC Staff perspectives enabled comparisons between the two APPE formats. Results: A total of 23 students participated: three at role-established and 20 at role-emergent sites. Evaluations indicated that all students successfully completed their learning objectives. Some differences were apparent - for example students at role-emergent sites expressed a desire for more one-to-one time with their pharmacy preceptor, but they also benefitted from more inter-professional collaboration and interacted with a broader range of health professionals than students with on-site APPE preceptors. Conclusions: This study demonstrated that equivalent but non-identical learning occurs at LTC locations with off-site preceptors (role-emergent) as in role-established hospital-based settings with on-site preceptors. Importantly, it also opens opportunities for many new APPE placement opportunities since there about three times as many LTC facilities as acute care hospitals in our jurisdiction.

\section{INTRODUCTION}

Experiential education (also referred to as practice education, fieldwork placement, and clinical practice) has been recognized as a cornerstone of allied health curricula. ${ }^{1}$ Through hands-on learning, students gain the opportunity to integrate theory and practice, crystallize professional skills, hone competencies, and explore new areas. Over the past several years, it has become increasingly difficult for allied health programs to attract and retain high quality experiential sites. ${ }^{1}$ In the context of such challenges, it has been necessary for programs to consider innovative experiential models to secure experiential placement sites. This paper examines one allied health program's initiative to addressing this complex problem. 
The standards set by the Accreditation Council for Pharmacy Education (ACPE) in the United States and by the Canadian Council for Accreditation of Pharmacy Programs in Canada require colleges and schools of pharmacy to introduce Introductory and Advanced Pharmacy Practice Experiences (IPPEs and APPEs) into their curricula that provide students with the opportunity to engage in direct-patient care with diverse patient populations and in multiple practice environments..$^{2-4}$ At the University of British Columbia in Canada, an office of Structured Practice Experiential Programs was instituted in 1999 with the primary aim to introduce direct-patient care learning activities into its experiential curriculum. To conform with the Canadian experiential requirements, 800 contact hours of experiential learning must occur across its 4-year curriculum. The IPPEs are scheduled at the end of the second and third academic years (each 160 contact hours) and take place within community pharmacies. Both APPEs occur in the final year of the four year baccalaureate program and are delivered as two courses - one in community pharmacy settings (320 contact hours) and the other in institutional settings (160 hours). Experiential learning is introduced in progressive fashion with students given increasing patient care experiences as they move from their first to the second IPPE and with greater patient care responsibilities expected during the final-year APPEs. The school's experience with expanding and introducing direct-patient care within its community-based APPE has been published elsewhere. ${ }^{5-7}$ This paper discusses the school's experiences with capacity building for institutional-based APPEs.

Prior to 2006, all institutional-based APPE placements at our University occurred at hospitals with on-site pharmacists and pharmacy departments to supervise students directly and on a regular basis, a model commonly referred to as "role-established" sites within the literature. ${ }^{8}$ However, as our experiential curricula expanded and greater emphasis was placed on direct-patient care activities and student-centered learning, it became increasingly challenging to recruit and retain quality hospital sites; a difficulty that was not unique to our school or to the profession of pharmacy. ${ }_{1,2}$ With pharmacy staff shortages across hospitals in British Columbia, concerns had been raised among hospital pharmacists how to accommodate increases in experiential placements and expectations. Limited placement capacities within hospital settings made it progressively more difficult for our school to meet accreditation expectations that require exposure to institutional patient care practice. It was therefore necessary to explore new strategies to enable students to gain relevant, good quality experiential learning.

Within British Columbia, Canada, there are approximately 25,000 beds in 390 Long-Term Care (LTC) facilities. ${ }^{9}$ People in LTC facilities have complex care needs and often depend on continuous nursing care. ${ }^{10,11}$ Services in these facilities typically include meals, medication storage and administration, regular assistance with activities of daily living (such as eating, mobility, dressing, bathing, grooming or personal hygiene), and routine medical care. Unlike hospital settings, only a small proportion of LTC facilities housed on-site pharmacy departments with full-time pharmacists to service residents in the facility and to provide continuous student supervision. The majority of LTC facilities are serviced by off-site community pharmacies offering full-fledged medication dispensing services but only limited direct patient care services. ${ }^{9}$ Experiential sites lacking on-site preceptors to supervise students have often been labelled in the literature as "role-emergent," self-directed, long-arm supervision, independent community placement, or non-traditional placement sites.8,12,13 To date, pharmacy students have had only limited exposure to LTC facilities due to a lack of appropriate experiential pharmacy training models within role-emergent settings, although other allied health professions (notably occupational therapy) have developed a broader spectrum of experiential training. ${ }^{14}$ Thus, LTC facilities offered a unique opportunity for building both student and institutional capacity.

With seniors now entering LTC facilities at more advanced ages, with greater health concerns, more concurrent disease states, and multiple medications, all of which have been associated with increased risk for drug-related morbidity and mortality, such sites offer an added opportunity to cultivate pharmacy students' competencies to promote appropriate, safe, and effective use of medications in the elderly..$^{15-17}$ At the outset of this project, there was no mandatory geriatrics course in the entire four year pharmacy curriculum, although one elective course in geriatrics was available and enrolled approximately a quarter of the students in their final year. By expanding the definition of "institutional sites" to include LTC facilities, this study also addressed an important educational gap in the pharmacy curriculum.

For this project, a pharmacy faculty team designed, developed, and evaluated an innovative institutional APPE model for LTC facilities serviced remotely by pharmacists. While student experiences with role-emergent placements in allied professions such as occupational therapy and nursing have been reported elsewhere, this paper reports pharmacy students' experiences within a new APPE model for institutional pharmacy placements. ${ }^{18}$

\section{METHOD}

A demonstration project developed and evaluated a LTC APPE for final-year pharmacy students at the University of British Columbia in Canada. The project was carried out over three academic years from August 2005 to May 2008 and consisted of two phases: a development phase which occurred between August to November 2005 and an evaluation phase which lasted 
from January 2006 to May 2008. Prior ethics approval had been obtained from the Office of Research Services at the University of British Columbia.

\section{Participants}

Seven LTC sites were recruited for this demonstration project: two hospital-based and five community pharmacy-affiliated LTC facilities. This distribution reflected the current service model within British Columbia where the majority of LTC facilities are serviced by off-site pharmacists associated with community pharmacies. Given their lack of on-site pharmacy preceptors, these 5 sites are labelled role-emergent. In contrast, the two hospital-affiliated LTC facilities were serviced by an in-house pharmacy department staffed by full-time pharmacists who were available to provide continuous supervision to pharmacy students during their APPE. These sites are referred to as role-established in the literature and in this paper. Since the two hospital-based facilities had previously served as institutional APPE sites and their pharmacists had advanced training and experience with caring for senior patients, they were recruited initially to help define a LTC APPE syllabus during the project's development phase and then later as part of the evaluation process. Recruitment was done by community pharmacy preceptors and involved meeting with the LTC facilities' administrators and facility staff to discuss the APPE program, students' activities, and to obtain their buy-in. While a few of the ancillary services differed among facilities, all residents (hence all students) had access to a physiotherapist, a dietician, a podiatrist, a registered nurse, and medical care provided by the facility physician. Residents from one of the role-emergent (off-site preceptor) facilities received their medical care from their personal off-site physician and their nursing care from a licensed practical nurse instead of a registered nurse. Residents' charts at all facilities served as an important tool for pharmacists to document their care at all but one role-emergent LTC facilities. As part of our school's remuneration policy, all pharmacies received a stipend of $\$ 50.00 \mathrm{CDN}$ for a four week student experience.

Placement at the LTC facilities for the first year (January - May 2006) was voluntary because the educational model for the roleemergent institutional APPE was still new and not yet tested. Students were invited to participate through email and class presentations. In that initial year, the first three students to express interest were recruited and placed randomly at one of the participating LTC facilities. For subsequent academic years, students were randomly placed at either a LTC or a tertiary care hospital site for their institutional APPE. Students received no remuneration for their experience. In all, 23 students participated in the pilot study which ran between January 2006 and April 2008.

\section{Intervention}

The learning activities for the LTC APPE are outlined in Table 1. Preceptors received the 150-page APPE manual outlining these activities and participated in a face-to-face workshop to discuss students' and preceptors' expectations, student evaluation processes, policies, and patient care tools. Additionally, preceptors participated in a preceptor education program designed to developed competencies specific to the care of elderly patients. The program used a case built on an existing "Care of Elders Delirium Module" developed at the University of British Columbia to promote inter-professional collaboration. ${ }^{19}$ The case was delivered using lectures, small group discussions, and exercises requiring preceptors to identify drug and non-drug related issues and to develop care plans for these issues. The module presented conditions commonly encountered among elderly patients in LTC facilities including delirium, depression, dementia, urinary incontinence, urinary tract infection, anemia, pain control, chronic heart failure, atrial fibrillation, stroke, renal failure and alcohol withdrawal. In addition, it addressed implications of pharmacokinetic and pharmacodynamic changes in the aged and provided an overview of common geriatric assessment tools. During the APPE, preceptors were supported through site-visits, telephone calls, and written e-mail or webmail communications on an as-needed basis. 
Table 1. Student Learning Activities at the Long-Term Care Facilities (4-Week Experience).

\begin{tabular}{|c|c|}
\hline Learning Activities & Minimums \\
\hline $\begin{array}{l}\text { 1. Provide Comprehensive pharmaceutical care: } \\
\text { - Assess and identify drug-related problems (DRPs) } \\
\text { - List all actual and potential DRPs } \\
\text { - Create an initial care plan for each DRP and discuss with pharmacy preceptor } \\
\text { - Collaborate with physician/facility staff and/or patient to resolve or prevent the DRPs. } \\
\text { - Provide follow-up to all patients }\end{array}$ & $\begin{array}{l}3-5 \text { patients } \\
\text { over } 4 \text { weeks }\end{array}$ \\
\hline $\begin{array}{l}\text { 2. Participate in Drug Review Process: } \\
\text { - Participate in daily drug review process by reviewing patients' medication profiles on } \\
\text { designated unit } \\
\text { - Assess for DRPs } \\
\text { - Identify and list all actual and potential DRPs } \\
\text { - Create an initial care plan for each DRP and discuss with pharmacy preceptor } \\
\text { - Collaborate with physician/facility staff and/or patient to resolve or prevent the DRPs. }\end{array}$ & $\begin{array}{l}2-8 \text { hours } \\
\text { over } 4 \text { weeks }\end{array}$ \\
\hline $\begin{array}{l}\text { 3. Conduct Allergy Assessments: } \\
\text { - Assess patients for drug allergies } \\
\text { - Discuss allergies with pharmacy preceptor } \\
\text { - Discuss allergies with physician/facility staff } \\
\text { - Document all allergies on the form provided }\end{array}$ & $\begin{array}{l}4-5 \text { patients } \\
\text { over } 4 \text { weeks }\end{array}$ \\
\hline $\begin{array}{l}\text { 4. Provide Medication Teaching: } \\
\text { • Provide medication teaching to patients and their families }\end{array}$ & $\begin{array}{l}4-5 \text { patients } \\
\text { over } 4 \text { weeks }\end{array}$ \\
\hline $\begin{array}{l}\text { 5. Provide Presentations to the facility staff: } \\
\text { - On a patient case to which comprehensive pharmaceutical care has been provided } \\
\text { - On a topic of interest }\end{array}$ & $\begin{array}{l}1 \text { of each type of } \\
\text { presentation } \\
\text { over } 4 \text { weeks }\end{array}$ \\
\hline $\begin{array}{l}\text { 6. Conduct Critical Appraisal of the Literature: } \\
\text { - Critically review one article relevant to care of your patients and discuss with pharmacy } \\
\text { preceptor } \\
\text { - Document the appraisal on the form provided. }\end{array}$ & $\begin{array}{l}1 \text { critical review } \\
\text { over } 4 \text { weeks }\end{array}$ \\
\hline $\begin{array}{l}\text { 7. Provide Drug Information: } \\
\text { - Work-up patient specific drug information questions raised by staff at the facility. } \\
\text { - Document all drug information questions on the form provided. }\end{array}$ & $\begin{array}{l}3 \text { drug information } \\
\text { workups over } 4 \text { weeks }\end{array}$ \\
\hline $\begin{array}{l}\text { 8. Engage in Inter-professional Collaboration: } \\
\text { - Participate in patient care-conferences }\end{array}$ & Daily and on-going \\
\hline $\begin{array}{l}\text { 9. Participate in Drug Distribution at the long-term care facility: } \\
\text { - Discuss drug distribution system with pharmacy preceptor } \\
\text { - Observe Nurse and Unit Clerk in distribution process } \\
\text { - Participate in processing and clarification of medication orders at the designated unit }\end{array}$ & Daily and on-going \\
\hline $\begin{array}{l}\text { 10. Understand Medication Management Processes and Protocols at the facility: } \\
\text { - Discuss programs at the institution to improve the quality of drug use, for example: drug } \\
\text { utilization programs, adverse drug reporting protocols, etc } \\
\text { - Discuss formulary system }\end{array}$ & $\begin{array}{l}\text { No minimum, as time } \\
\text { permits }\end{array}$ \\
\hline 11. Participate in other activities identified as appropriate by pharmacy preceptor & $\begin{array}{l}\text { No minimum, as time } \\
\text { permits }\end{array}$ \\
\hline
\end{tabular}

\section{Student preparation}

Student pre-preparation was essential for effective use of time at LTC facilities to meet their learning outcomes.8,12,13 Students received the same APPE manual as their preceptors, and they participated in a three-hour pre-APPE orientation session delivered by the school's experiential faculty to discuss the activities and expectations. In the project's first cycle and prior to the start of the LTC APPE, a separate three day workshop ensured that students had sufficient baseline knowledge to work independently and to contribute to the care of their elderly patients. The workshop used the same Care of the Elder module together with the pharmacy tool kit developed for the preceptors. However in subsequent cycles, students attended the preceptor education program, learning side by side with preceptors about topics pertinent to the care of elderly patients. Overall, the 
APPEs for role-emergent LTC locations were expected to be less structured than in other institutional settings thus requiring students to be more self-directed.

As part of their requirements, all students developed learning contracts at the beginning of their APPE outlining their learning needs and how they planned to address them. Students also maintained learning portfolios that included documentation of their patient care experiences: care plans, drug information requests, case presentation summaries, critical appraisal of the literature, activity schedules, and collaboration reflection forms. On completion of the rotation, students' learning portfolios were submitted to the APPE faculty for assessment prior to assigning their pass/fail final grades. Students and preceptors met for face-to-face discussions at least one-half day per week during which preceptors provided direct supervision and carried out formal assessments of the student's findings, care plans, and recommendations. Written care plans, drug information responses and consultation notes to the physician were emailed to the preceptor for feedback prior to dissemination. Before discussing any drug therapy recommendations with health care team members, students were required to first consult with their preceptor. Webbased technology using Adobe Connect ${ }^{\mathrm{TM}}$ (formerly Macromedia Breeze ${ }^{\circledR}$ ) software was introduced at the facilities and the community pharmacy sites to provide preceptors and students with additional communication options for email, telephone, and face-to-face discussions.

\section{Data Collection}

A 3-prong evaluation strategy guided the data assembly and analysis. Both qualitative and quantitative methods obtained feedback from students, which were combined with external review and analysis of their portfolio materials by an APPE faculty member and the project team. Survey questions required students to select responses from predefined scales, but they then further clarified their thoughts using open-ended responses to questions posed at the end of the surveys. Students completed two surveys. The first was a two part survey where they used a 3-point scale to rate the perceived importance to their learning of 8 site resources and 13 learning activities: ( 3 = High Importance, 2 = Moderate Importance, $1=$ Low Importance), then to report how well each activity or resource had facilitated their learning using a similar three point scale: (3=Very Well, 2=Fair, 1=Poor). In the second survey, students used a 3-point scale to assess how well each of 13 APPE pre-defined learning objectives had been achieved: (3=Definitely Occurred, 2=Partially Occurred, 1=Did Not Occur).

\section{Analysis}

The study assessed the APPE's impact on students by comparing and contrasting various perceptions of their experiences. Responses were transferred onto a spreadsheet (Microsoft Excel 2000) and analyzed both quantitatively and qualitatively. Despite small numbers, descriptive statistics (frequencies, means, and standard deviations) on the LTC facilities characteristics and survey questions were computed via SPSS v17 (IBM, 2010) and quantitatively analyzed. Mann-Whitney tests for small samples contrasted student responses in role-established settings from those in role-emergent placements although results are reported as means (and differences) of independent-sample t-tests because most readers are more familiar with differences between means than with probabilities of sampling symmetries. Free-form and open-ended responses were categorized thematically and analyzed. All identifiers were removed to maintain anonymity of participants.

\section{RESULTS}

The seven LTC facilities that participated in this study - two role-established and five role-emergent -- created 23 institutional APPE placement sites from January 2006 to May 2008, three students at role-established and 20 at role-emergent sites. The two role-established sites each took one student per academic year, with one site dropping out after the first cycle. The roleemergent (with off-site preceptor) locations started with one student in the first cycle, with some sites increasing their student number up to six per academic in subsequent cycles.

Students at the role-emergent LTC facilities were exposed to a broad range of experiences with opportunities very similar to those at the role-established LTC facilities. Table 2 shows slight but non-significant overall differences between both what students had deemed to be important and what they actually experienced and between role-established versus role-emergent sites. Quantitative ratings of their "actual" experiences differed significantly for seven of the 21 skills development activities and for five of their "importance" ratings. Averages for all 21 activities collectively did not distinguish significantly between students at role-established (preceptor on-site) and role-emergent locations with preceptors off-site. The learning expectations most difficult to meet for role-emergent sites included having adequate access to the Internet (1.5 out of 3 ) and drug information resources (1.7 out of 3), although internet access problems were limited to two of the five role-emergent sites. Limited access to residential patients was voiced by students at both role-emergent and role-established sites. Though the sites provided varying degrees of opportunity to collaborate with other students, such inter-student collaboration was deemed to be of low-importance by the students and neither strongly expected nor much experienced. 
Table 2. Students' Perspectives ( $\mathrm{N}=23$ ): Expectations vs. Experiences for Skills Development at Long-Term Care APPE Sites.

\begin{tabular}{|c|c|c|c|c|c|c|}
\hline \multirow{2}{*}{$\begin{array}{c}\text { Site Capabilities, Resources and } \\
\text { Activities to Facilitate Skill } \\
\text { Development }\end{array}$} & \multicolumn{3}{|c|}{ Deemed Importanta } & \multicolumn{3}{|c|}{ Actually Experienced ${ }^{b}$} \\
\hline & $\begin{array}{l}\text { Estab- } \\
\text { lished }\end{array}$ & $\begin{array}{c}\text { Emer- } \\
\text { gent }\end{array}$ & $\begin{array}{l}\text { Sig } \\
p<\end{array}$ & $\begin{array}{l}\text { Estab- } \\
\text { lished }\end{array}$ & $\begin{array}{l}\text { Emer- } \\
\text { gent }\end{array}$ & $\begin{array}{l}\text { Sig } \\
p<\end{array}$ \\
\hline $\begin{array}{l}\text { 1. Access to patient medical } \\
\text { records to create a patient- } \\
\text { specific database }\end{array}$ & 3.00 & 3.00 & ns & 3.00 & 2.90 & ns \\
\hline $\begin{array}{ll}\text { 2. } & \text { Patient care opportunities to } \\
\text { identify/resolve medication } \\
\text { related problems }\end{array}$ & 3.00 & 3.00 & ns & 2.67 & 2.45 & ns \\
\hline $\begin{array}{l}\text { 3. Collaborate with nursing staff } \\
\text { on patient care issues }\end{array}$ & 3.00 & 2.85 & ns & 3.00 & 2.68 & .010 \\
\hline $\begin{array}{l}\text { 4. Monitor patient response to } \\
\text { medication therapy }\end{array}$ & 3.00 & 2.85 & ns & 2.67 & 2.35 & ns \\
\hline $\begin{array}{l}\text { 5. Attend patient care rounds or } \\
\text { patient conferences }\end{array}$ & 3.00 & 2.75 & ns & 3.00 & 2.15 & .000 \\
\hline $\begin{array}{l}\text { 6. Interview patients, caregivers } \\
\text { and/or family members }\end{array}$ & 2.33 & 2.85 & ns & 2.33 & 2.35 & ns \\
\hline 7. Interpret laboratory data & 3.00 & 2.74 & .020 & 2.67 & 2.37 & ns \\
\hline $\begin{array}{l}\text { 8. Availability of pharmacy } \\
\text { preceptor }\end{array}$ & 3.00 & 2.65 & .005 & 3.00 & 2.05 & .000 \\
\hline $\begin{array}{l}\text { 9. Patient specific drug } \\
\text { information }\end{array}$ & 3.00 & 2.55 & .004 & 2.67 & 2.30 & ns \\
\hline $\begin{array}{l}\text { 10. Understand physical } \\
\text { examination skills }\end{array}$ & 2.67 & 2.65 & ns & 2.33 & 2.20 & ns \\
\hline $\begin{array}{l}\text { 11. Computer and internet access } \\
\text { for information retrieval }\end{array}$ & 3.00 & 2.45 & .002 & 3.00 & 1.50 & .000 \\
\hline $\begin{array}{l}\text { 12. Practical pharmacokinetics (e.g. } \\
\text { digoxin, warfarin monitoring) }\end{array}$ & 2.67 & 2.55 & ns & 2.67 & 2.00 & ns \\
\hline $\begin{array}{l}\text { 13. Access to tertiary, secondary, } \\
\text { and primary resources }\end{array}$ & 2.67 & 2.50 & ns & 3.00 & 1.70 & .000 \\
\hline $\begin{array}{l}\text { 14. Collaborate w/other allied } \\
\text { health professionals on patient } \\
\text { care issues }\end{array}$ & 2.67 & 2.50 & ns & 2.33 & 2.25 & ns \\
\hline $\begin{array}{l}\text { 15. Provide patient educ \& med } \\
\text { counselling to achieve optimal } \\
\text { patient outcomes }\end{array}$ & 2.67 & 2.50 & ns & 2.00 & 1.80 & ns \\
\hline $\begin{array}{l}\text { 16. Document a pharmacy care } \\
\text { plan to physicians }\end{array}$ & 2.33 & 2.45 & ns & 2.33 & 2.16 & ns \\
\hline $\begin{array}{l}\text { 17. Access to laboratory data to } \\
\text { create a patient-specific } \\
\text { database }\end{array}$ & 3.00 & 2.25 & .000 & 2.33 & 2.25 & ns \\
\hline $\begin{array}{l}\text { 18. Deliver presentations to other } \\
\text { pharmacists or allied health } \\
\text { professionals }\end{array}$ & 2.67 & 2.25 & ns & 3.00 & 2.40 & .000 \\
\hline $\begin{array}{l}\text { 19. Critical appraisal of the } \\
\text { literature }\end{array}$ & 2.33 & 2.11 & ns & 3.00 & 2.11 & .000 \\
\hline 20. Delivering nursing in-services & 1.67 & 2.10 & $\mathrm{~ns}$ & 2.33 & 2.35 & ns \\
\hline $\begin{array}{l}\text { 21. Availability of other students at } \\
\text { the site }\end{array}$ & 1.67 & 1.80 & ns & 1.33 & 1.80 & ns \\
\hline $\begin{array}{l}\text { Averages for } 21 \text { Site, Resource, } \\
\text { and Activity Features }\end{array}$ & 2.68 & 2.56 & ns & 2.60 & 2.33 & ns \\
\hline
\end{tabular}


Table 3 shows a similar pattern for the pre-defined APPE learning objectives. All university-established objectives were met by students at both types of facilities irrespective of their role-established or role-emergent histories, with slight but non-significant overall differences. This was confirmed by both students (in Table 3) and the experiential faculty who reviewed the students' learning portfolios which included documentation records of patient care experiences in which they had participated. The table notes two objectives where the groups differed: interacting with patients and healthcare providers to improve clinical skills, and understanding pharmaceutical care applications in the practice settings. As well, the table notes another two instances where students at role-emergent sites fractionally outperform their role-established peers: integrating undergraduate information in assessing and resolving drug-related problems and developing interview skills to obtain patient information. So while some of the students' expectations may have not been fully met as indicated in Table 2, the university-established objectives were met by all students at all LTC facilities irrespective of their role-established or role-emergent histories.

Table 3. Student Self-Reports Contrasting Role-Established with Role-Emergent Sites: Learning Objectives Achieved at Long-Term Care APPE Sites $\left(\mathrm{N}=20^{*}\right)$

\begin{tabular}{|c|c|c|c|}
\hline Mean Self-Reports for Thirteen Pre-Defined Learning Objectives & $\begin{array}{c}\text { Role } \\
\text { Established }\end{array}$ & $\begin{array}{c}\text { Role } \\
\text { Emergent }\end{array}$ & Sig. \\
\hline $\begin{array}{l}\text { 1. Develop problem solving skills to assess drug therapy, medical conditions, } \\
\text { and identify drug related problems (DRPs) }\end{array}$ & 3.00 & 3.00 & ns \\
\hline $\begin{array}{l}\text { 2. Develop documentation skills using a pharmacy care plan, including DRP, } \\
\text { recommendation, monitoring and follow up }\end{array}$ & 3.00 & 2.94 & ns \\
\hline 3. Develop inter-professional communication and working relationship skills & 3.00 & 2.94 & ns \\
\hline $\begin{array}{l}\text { 4. Develop professional maturity in order to contribute to patient care and } \\
\text { societal benefits }\end{array}$ & 3.00 & 2.88 & ns \\
\hline $\begin{array}{l}\text { 5. Develop communication skills to establish pharmacist-patient therapeutic } \\
\text { relationship and empathy }\end{array}$ & 3.00 & 2.82 & ns \\
\hline 6. Develop ability to prioritize DRPs in order they should be addressed & 3.00 & 2.82 & ns \\
\hline $\begin{array}{l}\text { 7. Integrate undergraduate didactic information in the assessment and } \\
\text { resolution of DRPs }\end{array}$ & 2.67 & 2.88 & ns \\
\hline 8. Continue developing therapeutic knowledge base and disease processes & 3.00 & 2.82 & ns \\
\hline 9. Expand exposure to patient records to provide patient care & 3.00 & 2.82 & ns \\
\hline 10. Develop interview skills to obtain relevant patient information & 2.67 & 2.71 & ns \\
\hline $\begin{array}{l}\text { 11. Interact with patients and healthcare providers to improve clinical skills and } \\
\text { increase confidence }\end{array}$ & 3.00 & 2.65 & $p<.000$ \\
\hline 12. Understand pharmaceutical care and its application in the practice setting & 3.00 & 2.63 & $p<.000$ \\
\hline $\begin{array}{l}\text { 13. Understand "real" and "perceived" barriers to providing pharmaceutical care } \\
\text { in practice and how they may be overcome }\end{array}$ & 2.67 & 2.59 & ns \\
\hline Combined Learning Objectives Total & 2.92 & 2.81 & ns \\
\hline
\end{tabular}

Students' qualitative results corroborated their numerical reports. In their open-ended reflections, students at the role-emergent sites noted how their APPE had contributed to personal and professional growth.

[The APPE] has given me perspective into the increased level of care that is needed when treating elderly patients, and it has allowed me to see all aspects of their care ... it has given me exposure to the hospital based practice of pharmacy and shown me the interface between community and (residential care) practice.

Although my clinical rotation was probably a lot different than what a typical hospital rotation is, it provided a lot of room for learning and growth. It really built up confidence as the majority of time I was working independently solving DRPs. Also, it provided a patient population that were interested in interacting with a pharmacist and were available for follow up. I had a really great experience. 
Students also commented that inter-professional collaboration with the facility staff was integral to their learning and patient care delivery experience.

I had a very good experience at [the LTC facility]. I was able to interact with a number of different members of the health care team including dieticians, nurses, and physicians ... The staff ... were extremely kind and helped me when I required it.

They [LTC staff] made me feel like a really valuable asset they had and that helped me feel comfortable in working there

[Strength of this experience was the] opportunity to work with different health care professionals in order to identify, address and resolve drug related issues. Staff was very willing to collaborate with pharmacy student for the benefit of the residents

[The Inter-professional team members] are an invaluable resource to pharmacists especially when involved in providing comprehensive care as they act as the "eyes and ears" at the site and can give insight into a patient's history. This is particularly important in the elderly population where dementia is common and the patient may not be able to account for all the necessary information.

By attending the resident care conference ... patient issues would be brought forward that were not documented in the chart and this would influence the medication recommendations for the patient ... [The same student rated the LTC experience as excellent and shared reason] working with other healthcare providers on a daily basis to improves patient outcomes.

There is ample opportunity to learn from a variety of healthcare professionals. The pharmacy ... as well as ... other [LTC] staff are very friendly to each other and I felt a sense of team spirit in this hospital. The doctors were very open to the pharmacists' thoughts and were willing to listen to my recommendations. I also very much enjoyed my collaboration activities with the registered dietician and physiotherapist because they were very good about explaining their roles in the hospital, and I also felt that they wanted to know how better to liase with pharmacy to provide care to the patients.

There was ample opportunity to speak and consult with physicians and nurses on patient care related issues .... I did a nursing in-service and I presented my primary literature evaluation and case presentation. Each time, I was offered valuable input and I felt more and more confident with each presentation.

Students also indicated that the inter-professional experience gave them a better understanding of their professional role and identity, as one student wrote:

This experience has opened my eyes to the importance of the pharmacist's role in patient care related decisions. I believe this experience has increased my confidence and provided me with useful clinical knowledge.

\section{DISCUSSION}

To our knowledge, this is the first study in pharmacy education to evaluate and document the impact on students' experiential learning of an APPE structured at role-emergent LTC institutions where pharmacy preceptors are off-site and not always onhand for interaction with students. Student evaluations suggest the role-emergent LTC facilities offered experiences and learning opportunities that were largely equivalent to role-established sites. Additionally, the role-emergent sites presented students with unique opportunities to engage in inter-professional collaboration and hone competencies related to the care of elderly patients.

Reviews of the students' learning portfolios and surveys confirmed that the role-emergent LTC APPEs provided students with experiences comparable to role-established LTC sites, and both models effectively met the institutional APPE standards and expectations. Preceptors in both pharmacy APPE models were able to expose students to a variety of patient care activities. Students regularly reviewed patient charts and medication administration records to assess drug-related issues, made drug 
therapy interventions for their patients during case conferences, shadowed other health professionals, interviewed patients, provided follow-up care, provided educational sessions to the nursing staff, participated in bed-side rounds with the physician, and responded to drug information questions, and each presented one patient case to the staff.

An unintended, but positive outcome of the LTC APPE experience particularly at the role-emergent facilities was the amount of inter-professional collaboration that became integral to the students' learning. The limited on-site access to pharmacy preceptors at the role-emergent sites combined with a well-thought-out approach by the school to support pharmacy preceptors through workshops and discussion was a likely key to the development of an inter-professional collaborative learning environment. This particular structure offered unique opportunities for students to be self-directed in their learning and to engage regularly with their facility's staff. Students were oriented to their facility and introduced to its staff by their pharmacy preceptor at the start of the APPE to facilitate collaboration, and staff were provided with a detailed overview of activities students were expected to complete.

To ensure continuous accessibility of students to the LTC staff (and vice versa), students were assigned to specific nursing units and were stationed where all medical and medication orders were processed and patient notes charted by staff. Many of the student learning activities in themselves promoted collaboration between students and staff, enabling discussions relating to treatment plans and patient specific drug-related issues. Example of some such activities include working alongside the unit clerk and nursing staff to process and clarify medication orders, reporting to the nurse in-charge to obtain patient referrals, shadowing LTC staff, participating in inter-professional patient care conferences, delivering educational programs to staff on topics of their interest, and providing medication teaching to patients, families, and staff. In these contexts, students carried out their learning activities as an integrative practice style rather than working in "silos."

Other non-pharmacy health care professionals willingly facilitated student learning and many took on a role of surrogate preceptor. The off-site pharmacy preceptors also demonstrated a more consultative and supportive role, periodically interacting with students to review and approve their recommendations prior to implementation. All students gave high ratings to their interactions with the nursing and allied health professional staff (Tables 2 and 3), and indicated that this collaboration had contributed significantly to their learning. In their written feedback, students noted that they now had an increased knowledge of different health professionals as a result of their diverse interactions, they felt more confident and comfortable in working with other professionals to improve patient outcomes, and they had gained greater understanding of their role as pharmacists within an inter-professional setting.

Our findings differed from that of Guirgis et al and Morello et al who viewed the presence of an on-site pharmacist preceptor as necessary to facilitate inter-professional experiences, whereas in this role-emergent project, inter-professional collaboration and learning was a natural consequence of the placement/preceptoring combination. ${ }^{20,21}$ Some of the differences may result from our detailed pre-planning and organized approach where the very structure of the LTC APPE necessitated inter-professional collaboration and cross-disciplinary learning. Unlike the Guirgis et al and Morello et al studies, placement in this project was limited to senior year APPE-ready students who already had previous IPPE engagements in experiential learning and therefore some understanding of health professional roles. ${ }^{20,21}$ Additionally, this project supported preceptor (as well as student) learning by providing all pharmacy preceptors a pre-LTC APPE workshop and on-going meetings/discussions with study and APPE faculty to outline student orientation procedures to the LTC facility and staff occurred as planned and to ensure that the predetermined student learning activities were integrated within the day-to-day patient care delivery activities at the LTC facilities.

While there is a paucity of pharmacy literature investigating role-emergent placements, the few occupational and physiotherapy publications that that have examined off-site preceptors describe similar benefits. $8,12,13,16$ Some of the benefits have included independence and autonomy - both of which promote personal growth, honing of self-directed learning and problem-solving skill, opportunity to engage in expanded roles within the profession and for role-development, and opportunity for inter-professional communication and collaboration. However, to fully realize the benefits offered at role-emergent APPEs with off-site preceptors, the literature proposes that such placements be limited to senior level students who bring knowledge, skills, and experience gained from earlier placements. Pharmacy students participating in this study confirmed this by noting that student preparation and professional maturity was essential for a successful placement. At our school, this problem was mitigated by limiting this experience to senior students completing their APPE. Whether or not students at the IPPE level would perform as well is unknown.

However, there were some challenges experienced by students at role-emergent LTC placements with off-site preceptors. Students reported how they were uncertain at the beginning of their APPE experience how to begin engaging in patient centred activities at their facilities, needing more feedback on how to efficiently acquire relevant patient information during interview

(C) The Internet Journal of Allied Health Sciences and Practice, 2013 
processes, and having insufficient opportunities to engage in one-on-one patient education - particularly medication-related information. Three (of the 20) students from the same role-emergent site commented they would have preferred more one-onone time with their preceptors even though s/he met the minimum preceptor-student face-to-face teaching expectation set by the school. For all APPEs, preceptors are requested to allocate a minimum of four to six hours of face-to-face teaching time per week with their students -- in addition to time spent facilitating learning opportunities and supervising students learning - which may happen ad-hoc. Since these shortfalls depend on preceptor-student mentoring and modeling, a few student dissatisfactions were not surprising. Preceptors at the two hospital-based sites had had prior experience precepting students, but for the five offsite pharmacy preceptors at the role-emergent locations, this was their first precepting experience of APPE students within LTC settings, so both students and preceptors were faced with interdependent learning curves.

Students also noted the lack of opportunity to provide one-on-one patient education. Since the need for educational in LTC settings is most often dictated by residents' cognitive status and personal desire for such education, this limitation had more to do with the patient population to whom the students delivered care than with the role-emergent model itself. Given the residents' advanced age at most of the LTC facilities, concurrent disease states, and multiple medications, a majority required around the clock nursing care -- a situation not conducive to one-on-one patient education. Future student education and preceptor orientation will need to expand on the concept of patient education beyond just the one-to-one pharmacist-patient model to include family members and caregivers who play an active role in their elder's medical care and serving as their advocate within the health care system. Still, students expressed in their reflections that the APPE had helped them to develop greater confidence in caring for elderly patients and that they would consider a career within LTC settings as a result of this experience.

As recognized in the Institute of Medicine and the American Association of Colleges of Pharmacy Geriatric Special Interest Group reports, the need for pharmacists trained in geriatric care will continue to increase in the upcoming years.17,22-25 Given the enormous shift in population demographics, pharmacy curricula will need to ensure that professional practice-based and abilitybased outcomes consider competencies needed to care for the elderly. This will require classroom education in geriatric care as well as opportunities for students to apply their knowledge in settings of actual patient care in order to link theory to practice. In the absence of randomized controlled trials, this study cannot provide conclusive evidence on the effectiveness of on-site versus off-site preceptor models. However, the perception that one version is superior to another is based only on anecdotes and historical precedents rather than meaningful, robust, comparative studies. ${ }^{13}$ Given the sparse pharmacy research available, this study provides valuable insight about one school's experience with off-site preceptor (role-emergent) placement models. Our findings suggest that using locations with off-site preceptors (such as LTC facilities) as APPE sites can provide unique opportunities for students to hone competencies and interest in caring for patients in settings where the clarity of the various educational/training/supervising roles is still emerging.

\section{LIMITATIONS}

As with any study, a few limitations warrant mention. The first was the small numbers of both facilities and students. Second, the role-established community pharmacies participating in this study were both voluntary and self-selected. Hence, increased student experiences may be a reflection of more seamless APPEs facilitated by a motivated pharmacy preceptor group. Whether more mainstream preceptors can facilitate comparable positive experiences for students remains to be tested. Third, reporting bias cannot be ruled out. As with any cross-sectional study, some of the students may have been reluctant to report decreased satisfaction and to report -- in their own best interests -- that learning had occurred. Thus, it was reassuring to discover that the work submitted by students in their learning portfolios and assessed by the project team and APPE faculty validated the students' survey results.

\section{CONCLUSION}

Schools of pharmacy are charged to create experiential opportunities to prepare students to meet the growing needs of the populations they will serve. Providing quality experiences challenges schools to recruit and retain qualified practitioners willing to serve as preceptors. With hospitals experiencing pharmacy staff shortages, colleges and schools of pharmacy need to look beyond traditional hospital models to deliver institutional-based experiential learning. This study demonstrated that important learning can occur at role-emergent LTC facilities with off-site discipline specific preceptors.

As noted, both student and off-site pharmacy preceptor pre-preparation is essential for effective use of time at role-emergent sites and to meet the learning outcomes. With a mandatory geriatric course now introduced into the school's curriculum, future students will have better baseline knowledge needed for caring of older adults prior to their APPE and allowing APPE faculty to shift their efforts toward preparing students and preceptors specifically for role-emergent sites. Given limited access to pharmacy preceptors at LTC facilities, pre-APPE orientation must continue to ensure that students feel confident and able to work in a selfdirected and independent fashion. Future efforts should also continue to nurture the inter-professional learning and collaboration

(c) The Internet Journal of Allied Health Sciences and Practice, 2013 
that was observed in this study and to expand the model to other patient care facilities that lack on-site pharmacy preceptors, including rural and community dwelling sites.

\section{ACKNOWLEDGEMENTS}

This project was funded by the British Columbia Ministries of Health and Education through the British Columbia Academic Health Council. We would like to acknowledge Dr. Peter Jewesson for his editorial contribution to the grant proposal; Dr. Angela Kim-Sing in her role as institutional experiential coordinator, with student/preceptor recruitment and preparation; Dr. Martha Donnelly for permission to use the Care of Elders Delirium Module; Dr. Aaron Tejani, Dr. Rhonda Malyuk, Dr. Kiran Ubhi, Dr. Arun Verma, Ms. Mandeep Kooner, Dr. Angela Kim-Sing and Dr. Marianna Leung for assisting with the preceptor education program; Ms. Lenora Ho for assisting with literature review, Ms. Yvonne Sin for assisting with data collation, and all pharmacy preceptors, students and allied health staff who participated in this demonstration project.

\section{REFERENCES}

1. Association of Canadian Community Colleges. Sustaining the allied health professions: research report. Ottawa, Ontario, Canada. [Report on the Internet]. 2012 [cited 2012 October 23]. Available from: http://www.accc.ca/xp/index.php/en/programs/cdnpartnerships/ahealth/applied-research

2. Capacity of hospitals to partner with academia to meet experiential education requirements for pharmacy students. $A m \mathrm{~J}$ Pharm Educ. 2008;72(5):117. [PMID: 19214271].

3. American Council on Pharmaceutical Education. Accreditation Standards and Guidelines for the Professional Program in Pharmacy Leading to the Doctor of Pharmacy Degree. Chicago, Illinois, USA. [Report on the Internet]. 2011 [cited 2012 October 23]. Available from: https://www.acpe-accredit.org/pdf/FinalS2007Guidelines2.0.pdf.

4. Canadian Council for Accreditation of Pharmacy Programs. Educational Outcomes for First Professional Degree Programs in Pharmacy [Entry-to-Practice Pharmacy Programs] in Canada. Vancouver, British Columbia, Canada. [Report on the Internet]. 2012 [cited 2012 October 23]. Available from: http://www.ccapp-accredit.ca/obtaining_accreditation/

5. Kassam R, Kwong M. An enhanced community advanced pharmacy practice experience model to improve patient care. Am J Pharm Educ. 2009;73(2):25. [PMID: 19513163].

6. Kassam R. Evaluation of pharmaceutical care opportunities within an advanced pharmacy practice experience. Am J Pharm Educ. 2006;70(3):49. [PMID: 1636962].

7. Kassam R. Students' and preceptors' experiences and perceptions of a newly developed community pharmacy pharmaceutical care clerkship. Pharm Educ. 2006;6(3):179-88.

8. Bossers A, Cook J, Polatajko H, Laine C. Understanding the Role-Emerging Fieldwork Placement. Can J Occp Ther. 1997;64(2):70-81.

9. British Columbia Pharmacy Association. Report: Alternative compensation Systems for the Provision of Pharmacists' Services to Long-Term Care Facilities in BC. Vancouver, British Columbia: British Columbia Pharmacy Association. 2005.

10. Community Care Facilities Licensing Branch of the Government of British Columbia. A Guide to Choosing a Licensed Residential Care Facility or Residential Care Home. Victoria, British Columbia, Canada. [Report on the Internet]. 2001 [cited 2012 October 23]. Available from: http://www.health.gov.bc.ca/ccf/publications/com031.pdf

11. Canadian Healthcare Association. New Directions for Facility Based Long Term Care. Ottawa, Ontario: Canadian Healthcare Association. [Report on the Internet]. 2009 [cited 2012 October 23]. Available from: http://www.bccare.ca/pdf/CHA\%20\%20National\%20Report\%20on\%20Facility\%20Based\%20Long\%20Term\%20Care.pdf

12. Huddleston R. Clinical Placements for the professions allied to medicine, Part 2:Placement shortages? Two models that can solve the problem. Br J Occup Ther. 1999;62(7):295-8.

13. Lekkas P, Larsen T, Kumar S, Grimmer K, Nyland L, Chipchase L, et al. No model of clinical education for physiotherapy students is superior to another: a systematic review. Aust J Physiotherap. 2007;53(1):19-28.

14. Jones R, Jenkins F, eds. Developing the Allied Health Professional. Abington: Radcliffe Publications, 2006.

15. Zermansky AG, Alldred DP, Petty DR, et al. Clinical medication review by a pharmacist of elderly people living in care homes - randomized controlled trials. Age Ageing. 2006;35(6):586-91.

16. Overton A, Clark M, Thomas Y. A review of non-traditional occupational therapy practice placement education: a focus on role-emerging and project placements. British Journal of Occupation Therapy. 2009;72(7):294-301.

17. Odegard PS, Breslow RM, Koronkowski MJ, et al. Geriatric pharmacy education: a strategic plan for the future. Am J Pharm Educ. 2007;71(3):47. [PMCID: 1913301]

18. Gregory P, Quelch, L, Watanabe E. "The student experience of a role-emerging placement." In: Role-Emerging Occupational Therapy: Maximising Occupation-Focused Practice. Eds. Thew, M., Edwards, M., Baptiste, M., and Molinieux, M. Blackwell, Chichester: Blackwell, 2011.

19. Care for Elders Education Group. An interactive guide to the treatment of delirium. Vancouver, BC: University of British Columbia. [Internet]. 2010 [cited 2012 October 23]. Available from: Available at: http://www.careforelders.ca. 
20. Guirguis L, Sidhu K. An exploration of pharmacist preceptor's and pharmacy students' experiences at an interprofessional student-run clinic. CPJ. 2011;44(4):179-85.

21. Morello CM, Singh RF, Chen KJ, Best BM. Enhancing an introductory pharmacy practice experience at free medical clinics. Int J Pharm Pract.2010;18(1):51-7. [PMID 20405596]

22. Misiaszek BC, Borrie MJ, Grymonpre RE, et al. Canadian University Faculties of Pharmacy: Undergraduate Curriculum Survey of Geriatric Content. Am J Pharm Educ. 2001;65:231-5.

23. Committee on the Future Health Care Workforce for Older Americans. Retooling for an Aging America: Building the Health Care Workforce. Washington, DC: National Academy of Sciences. [Report on the Internet]. 2008 [cited 2012 October 23]. Available from: http://www.iom.edu.

24. Canada Senate. Special Senate Committee on Aging Final Report. Canada's Aging Population: Seizing the Opportunity. Ottawa, Ontario: The Senate, Ottawa. [Report on the Internet]. 2009 [cited 2012 October 23]. Available from: http://www.parl.gc.ca/Content/SEN/Committee/402/agei/rep/AgingFinalReport-e.pdf.

25. Romanow RJ. Commission on the future of health care in Canada. Building on values. The future of health care in Canada. Final Report. [Report on the Internet]. 2002 [cited 2012 October 23]. Available from: http://publications.gc.ca/site/eng/237274/publication.html

\section{KEY TERMS}

Residential Care, Pharmacy Students, Clerkship, Clinical Education, Advance Pharmacy Practice Experience, Fieldwork 